\title{
Writing a journal article from your thesis or research project
}

\author{
Jean Patterson ${ }^{A, B} P h D, M A, B A, R M ・$ Andrea Gilkison $^{C}$ PhD, MEd, RM
}

\author{
${ }^{\text {A Corresponding }}$ \\ Author: jean. \\ patterson@op.ac.nz \\ ${ }^{\mathrm{B}}$ Otago Polytechnic, \\ Dunedin \\ ${ }^{\mathrm{C}}$ Auckland \\ University of \\ Technology, \\ Auckland
}

\begin{abstract}
Background: Many midwives who have completed their thesis or dissertation have not subsequently published their findings in a peer reviewed journal. This means that the potential contribution of their research findings to midwifery knowledge does not reach a wider audience.

Aim: The aim of this paper is to alert prospective midwife authors to useful tips and writing strategies and encourage them to write and submit an article to a peer reviewed journal.

Discussion: Adapting a large manuscript to the size and shape required by a journal can be a daunting task, requiring trimming and rewriting. Some authors may also experience writer anxiety and a lack of practical support. These issues are addressed, and readers are alerted to steps and strategies for writing well and establishing a simple clear argument. We discuss the practical challenges and offer advice on making time to write, choosing a journal, enlisting the help of a co-author, preparing for submission, and responding to editor or reviewer comments.

Conclusion: It is our intention to assist midwives to publish their research, while acknowledging that this work needs to fit around already busy lives. In this article we address the personal and practical issues which may inhibit some midwives from writing, plus discuss tips and strategies to manage the writing tasks.
\end{abstract}

Keywords: midwifery research, writing anxiety, writing skills, writing for publication

\section{INTRODUCTION}

Many gems of well-crafted theses, with unique insights into midwifery practice and women's birth experiences, lie forgotten on shelves, never to see the light of day. Thus, our goal in this paper is to encourage these authors to dust off their work and write an article, based on their study, for publication in a peer reviewed journal. After all, much passion and hard work go into producing these works and the findings deserve to be in the public arena. So, if you have completed a research project, or a thesis, and have not yet published the outcomes, we hope this article will inspire you to do so.

We begin by considering some of the emotional and practical factors which may challenge prospective writers, and suggest strategies for managing them. We highlight resources which detail techniques for scholarly writing and teach you how to establish and maintain your voice and argument - including the challenge of downsizing a large manuscript into the confines of a publishable article. Practical tips are offered for planning the writing task, choosing co-authors and preparing your manuscript for publication. Finally, we advise on effective ways to respond to comments from editors and reviewers.

\section{COMMITTING TO WRITING}

Say goodbye to personal roadblocks

A common challenge for writers is anxiety about their ability to live up to the perceived expectations of others. Some may fear being exposed as a fake, despite having achieved outstanding academic and professional accomplishments. This so-called "imposter phenomenon" (Clance \& Imes, 1978) is frequently found among high achieving women who, despite evidence to the contrary, insist on perceiving themselves unworthy of their success.

While men may struggle with similar anxieties (Flora, 2016), the phenomenon appears to be especially common in women working in health-related fields. For example, reluctance to publish or take up promotion appears to be common among nurses, some of whom have expressed feelings of phoniness when stepping into an enhanced work role (Wood, 2018). Further, Walsh et al. (2016) lament the lack of writing confidence among dental hygienists, suggesting that in some instances the "queen bee" syndrome may be a problem. This syndrome, described by Staines et al. (1973), suggests that the queen bee is a woman who has succeeded in her career but refuses to help other women to do the same avoiding competition by associating predominately with her maledominated management group rather than with her female peers (Cooper, 1997).

Neither of these phenomena may apply to midwifery scholars who are new to publishing. Nonetheless, at times we are all capable of sabotaging ourselves with defeatist self-talk (Sherman, 2013). So, it is important to be realistic and acknowledge what we have achieved to date and what is possible for the future.

Scholarly writing and establishing your voice and argument We are all writers. We write for many different purposes and, with experience, learn what is expected in terms of style and detail. Similarly, writing a clearly worded and well-argued article for a 
journal is a learned skill. Understanding the basics of good writing and ways to establish and develop your argument are particularly important when converting your master's thesis or research project into an article. A good way to start is to read some recent articles from midwives who have published from their research in midwifery journals. This will help you see the size and shape required. However, it is important to realise that the well-crafted sentences and arguments in journals or book chapters have gone through many drafts, careful editing and proofreading before appearing on the shelf or in the journal.

Of course, journal articles need to be shorter than the theses they were derived from, so considerable trimming is needed. This is a time to be ruthless. Brychan and Skinner suggest that

\section{[T]o reframe a dissertation for a journal article requires a tight theoretical framework, a succinct literature review, a controlled presentation of the methodology, and concise discussion of the results. Since articles evolved from dissertations will be shorter, there is a need to trim the length of the dissertation. The process of trimming involves selecting and rewriting instead of cutting and pasting. For a journal article extraneous material must be removed, and substance needs to be preserved. (2012, p.4)}

Companion articles "Writing for publication; the basics" (Fahy, 2008b) and "Writing for publication; argument and evidence" (Fahy, 2008a) can help with this process. These articles provide detailed advice, with midwifery examples, on the basics of writing for publication and how to develop and maintain an argument. For example, they suggest that in the introduction the writer should start with the question or problem, summarise the relevant literature, define key terms and state the main message or thesis for the paper. This order logically and helpfully informs the reader of what to expect in the article.

Useful tips are to be found also in an article by Sarah Wickham in Essentially MIDIRS (Wickham, 2012). While she is not specifically discussing converting a thesis, the tips are useful for any writing project. Wickham suggests imagining that you are the editor looking for new and innovative ideas. Therefore, it is important to decide on your key points, or the bare bones, of your work with the goal of engaging your audience. (Of course, your first audience is the editor of your chosen journal.) Consider what kernels you will jettison, the style - first or third person - and the pivotal point in your story, in other words, nailing your argument. Thus, your best chance of succeeding in publishing your article is for your work to be clearly and concisely written with a well-developed and consistent argument throughout, supported by your research findings and appropriate references.

This advice is echoed in Belcher's (2009) workbook. The author provides detailed advice on planning and designing your article from start to submission, emphasising the importance of a clear research question or aim that is developed throughout the article. Further, Belcher stresses that your article must respond to the "so what" question. This means your article cannot be a ramble or based solely on your opinion. Rather, you need to support your argument by balancing and critiquing the arguments for and against your central thesis. One way to test your argument is by using the "instant thesis" (read "argument") approach:

Although... (general statement, opposite opinion)

Nevertheless, ... (your idea)

Because, ... (examples and evidence) (Belcher, 2009, p.89)
This should not be an emotional or philosophical stand, but one based on the rigour of the evidence you present. For example, it is important to avoid attacking a "straw man", where an opponent's position is misrepresented to make it easier to refute their preferred evidence. Hence, your argument should be set out clearly at the start and evidence presented in a balanced way, explaining why the preferred evidence is more compelling.

Style is important. You want your reader to be captured by your abstract and wanting to read more. To hook their reader, Freysteinson and Stankus (2019) encourage writers to adopt a simple storytelling style by crafting a simple, concrete introductory sentence that engages the audience. This is not to say that your article should not be complex and rigorous but, rather, that you understand "simple" as a "...means of cutting through a significant amount of data and information to find the simple story within the material" (Freysteinson \& Stankus, 2019, p.107). The story you are about to tell should be alluded to in the abstract and lead the reader into your work. Similarly, the conclusion should leave the reader satisfied that you have completed your story, while leaving an opening for the future.

\section{GETTING STARTED}

There is plenty of advice on how to get started on your article but, regardless of how long it is since you completed your thesis, it will be important to ensure that your article is up to date. For example, you will need to repeat your literature search for recent articles; i.e., those published in your field of interest since you completed your thesis (Student Learning Development, 2016). If you have not previously used an electronic referencing system, learning how to use one will be time well invested. Such a system enables you to upload articles and references directly from databases and other internet sources and quickly convert them into the journal's required referencing style.

How you tackle the often "messiness" of the drafting task will vary depending on what works best for you. This may be a structured process or one embracing a more fluid and individual style. For example, Belcher (2009) sets out a structured and reflective workbook for completing your article in 12 weeks; while Silvia (2017) suggests that you start with your introduction, then your overview, followed by your research project. Alternatively, Murray (2011) suggests that you avoid procrastination and just get something down on paper; i.e., start with an outline but then plunge in and say how you did your research and what you found. The introduction can be written last, outlining your aim, purpose and relevant background. In whatever order you choose to tackle the task, the final draft will need to contain the key elements of your research process and findings in a logical and readable way.

\section{Writing with others}

It may help to invite someone to travel with you on this journey. So do consider engaging the help of a willing colleague with previous publication experience, or your research supervisor. Most are keen to help get you published and it is a win/win for them too. They will become your co-authors and will have a vested interest in the quality of your work. It is expected that they will read and provide feedback on your drafts. In addition, you may also choose to organise, or join, a writing group. These can be energising and expose you to new ideas, resources and technical knowledge, such as formatting documents and reference management skills. So be realistic about what you know how to do and be ready to ask for help when you need it.

\section{Developing a writing habit}

We all have busy lives so fitting writing into your day is usually a challenge. Silvia (2017) agrees that writing is hard work but 
ruthlessly shatters some of our "specious barriers" to writing. These include: the complaint of not being able to "find" time, delaying writing for more and more analysis, or waiting until you have the muse and feel like it - all of which he asserts can be overcome by scheduling a time to write. In other words, he recommends "allotting" time for writing in the same way we allot time for other activities in our lives, as opposed to trying to "find" time for it.

On a lighter note, Kearns and Gardiner (2011) parody Samuel Beckett's play Waiting for Godot in their column titled, "Waiting for the Motivation Fairy". In the play where in fact Godot does not show up, similarly, the motivation fairy rarely appears. The authors suggest you ask yourself what is keeping you from writing and why is housekeeping so much fun when you really should be working on your article. This and other displacement activities can fill your day and distract you. Thus, a three-pronged attack is suggested. Firstly, you need to start writing before the motivation sets in. Secondly, break the work into tiny doable steps and, finally, promise yourself a reward when you have done some writing. Whether you use short regular bites, or carve out dedicated blocks of time, is up to you and your individual circumstances but it is important to keep plugging away at the task.

\section{PREPARING YOUR ARTICLE FOR YOUR SELECTED JOURNAL}

While you are writing your first draft you need to consider where you want to publish. Begin by visiting the websites of a range of preferred journals and read the advice for authors. Check the journal submission guidelines carefully. These will detail the types of articles accepted, required word count and referencing style. A good idea is to skim read a selection of articles on a range of topics and methodological styles to see how the authors have shaped their work for particular publications.

When you and your co-authors have agreed on the final version of your article, print a copy of it. Reading your text aloud and hand proofing enables you to check for minor spelling and grammatical errors, or any irritating text that you missed in the online version. Also, consider shortening or splitting any wordy sentences.

All journals have a process for submission and you may wish to enlist help if you find the process confusing. Once you have submitted, it is time to celebrate this significant step while you anticipate the response from the editor. You will be notified once your article has been sent for peer review. Peer reviewed journals will request two independent peers to review each article and, once the reviews are completed, the editor makes the decision about whether the article will be accepted or not, and what amendments are required. You will receive the reviewers' and editor's feedback, which is aimed to assist you to craft your article into an even better article. This process usually takes between 6-8 weeks.

\section{Responding to editor and reviewer comments}

Some of you, like us, have sent an article for review and been discouraged by the reviewers' comments.

\section{My first submission to a journal was rejected because I had tried to do too much in the one article. Once I recovered from the disappointment, I was able to see what the reviewers were saying and how I could split the material into three more focused articles, all of which were subsequently accepted for publication. This was a valuable lesson about keeping to a focused argument throughout and allowed for a richer text in each article. (J.P.)}

It is incredibly rare for an author to have an article accepted without any changes (Williams, 2004). Most editors will explain why the article is rejected, so this is good feedback for you. If changes are minor, then you can get on with them quickly and return your article. Major revisions will need more thought and collaboration with your co-authors. If the editor has suggested your article would be accepted with recommended changes, then that is great news. While the changes may seem overwhelming on first reading and just not worth the effort, put your work away for a few days before you tackle it. The recommended changes are probably not as difficult as you first thought. Most authors find that starting with the "low hanging fruit" enables them to ease into the changes, starting with the easy-to-fix bits and then tackling the comments which recommend or require more detail or structural changes (Williams, 2004).

Silvia (2017) suggests that we shouldn't fear rejection but rather embrace it as a step on the journey. Nonetheless, we are human and the candid quote below, written by an established author may be redolent of the range of emotions that authors may experience in response to rejection.

The rejection of my own manuscripts has a sordid aftermath:
(a) one day of depression; (b) one day of utter contempt for
the editor and his [sic] accomplices; (c) one day of decrying
the conspiracy against letting Truth be published; (d) one
day of fretful ideas about changing my profession; (e) one
day of re-evaluating the manuscript in view of the editors
[sic] comments followed by the conclusion that I was lucky
it wasn't accepted! (Underwood, 1957, p.87, as cited in
Belcher, 2009, p.291)

The three golden rules when responding to reviewer comments, according to Williams (2004), are to answer completely, answer politely, and answer with evidence. It is helpful to make a table with reviewers' comments on the left, and your responses on the right. Reviewers are human and may not always be right or may require further clarification to enable them to understand the point you were making. You do not have to agree with all the reviewer comments, but you do need to respond and state what you have changed or justify why you have not made a change. Useful phrases you could use in your response are, we agree with the reviewer that... but... Or, In accordance with the reviewers' recommendation we have now changed... These and other polite but clear responses acknowledge the reviewers' investment in your work and enable you to respectfully agree, or disagree, with their comments or recommendations.

Once you have responded to the reviewer comments, the article is returned to the editor, along with the documents the journal requires, such as the table you have created with the changes you have made. Sometimes, if there have been a lot of amendments needed, the article is sent back to the reviewers, or other times just the editor will check the changes you have made. If there are issues still to be addressed, the article will be sent back to you again until it is ready to be sent for proofreading and layout. During the proofreading and layout stage your article will be sent back to you with queries and corrections to be made until the final copy of your article is ready for publication. With online publishing, articles are usually available electronically straight away. Now is the time to celebrate the important contribution your research has made to the midwifery literature.

\section{CONCLUSION}

Many potential contributions to midwifery knowledge lie dormant in theses and research that have not been published and therefore are not readily accessible in the public arena. This article has highlighted some of the emotional and practical challenges that may inhibit potential writers from publishing their work. 
Addressed are the anxiety some may experience when exposing work to public scrutiny and suggestions for how to hone writing skills - in particular, the importance of establishing and maintaining a clear and well supported argument. The prospect of writing an article from a large manuscript presents unique challenges, and advice is offered on how to begin and maintain progress, including enlisting co-author support for the task. Practical advice is offered on preparation for submission and on how to respond to editor and reviewer comments in an efficacious way.

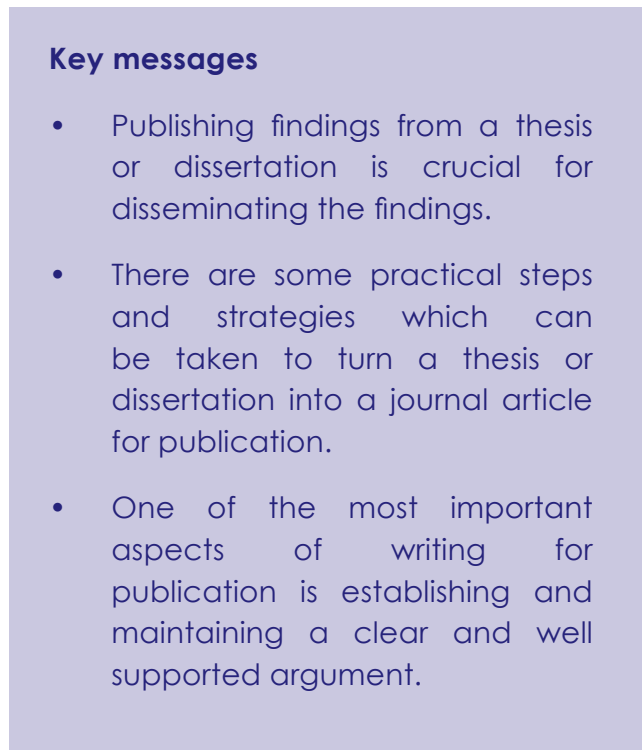

\section{ACKNOWLEDGEMENTS AND CONFLICT OF INTEREST DISCLOSURE}

The authors are editors of the New Zealand College of Midwives Journal. They declare that there are no conflicts of interest.

\section{REFERENCES}

Belcher, W. L. (2009). Writing your journal article in 12 weeks. A guide to academic publishing success. London: Sage.

Brychan, T., \& Skinner, H. (2012). Dissertation to journal article: A systematic approach. Education Research International, 2012. Article 862135. http://dx.doi.org.op.idm.oclc.org/10.1155/2012/862135

Clance, P. R., \& Imes, S. A. (1978). The imposter phenomenon in high achieving women: Dynamics and therapeutic intervention. Psychotherapy: Theory, Research \& Practice, 15(3), 241-247. https://doi.org/10.1037/ h0086006

Cooper, V. W. (1997). Homophily or the queen bee syndrome: Female evaluation of female leadership. Small Group Research, 28(4), 483-499. https://doi.org/10.1177/1046496497284001

Fahy, K. (2008a). Writing for publication: Argument and evidence. Women and Birth, 21(3), 113-117. Retrieved from http://search. ebscohost.com/login.aspx?direct=true $\& \mathrm{db}=\mathrm{ccm} \& A N=105665894 \&$ site $=$ ehost-live

Fahy, K. (2008b). Writing for publication: The basics. Women and Birth, 21(2), 86-91. https://doi.org/10.1016/j.wombi.2007.12.005

Flora, C. (2016). The fraud who isn't. Psychology Today,

Nov, 71-88. Retrieved from https://static1.squarespace.com/ static/59ca7af1ccc5c53642092a36/t/5b510ccd0e2e72f7a5389 ec5/1532038352167/PT150_imposer_70-88.pdf

Freysteinson, W. M., \& Stankus, J.-A. (2019). The language of scholarship: How to write an abstract that tells a compelling story. Journal of Continuing Education in Nursing, 50(3), 107-108. https://doi. org/10.3928/00220124-20190218-04

Kearns, H., \& Gardiner, M. (2011). Waiting for the motivation fairy. Nature, 472, 127. Retrieved from https://www.nature.com/articles/ nj7341-127a.pdf
Murray, R. (2011). Skillful writing of an awful research paper. Analytical Chemistry, 83(3), 633. https://doi.org/10.1021/ac2000169

Sherman, R. O. (2013). Imposter syndrome: When you feel like you're faking it. American Nurse Today, 8(5), 57-58. Retrieved from http:// search.ebscohost.com/login. aspx?direct=true $\& \mathrm{db}=\mathrm{ccm} \& A N=104290879$ \&site $=$ ehost-live

Silvia, P. J. (2017). How to write a lot. A practical guide to productive academic writing (1st ed.). Washington USA: APA Life Tools.

Staines, G., Travis, C., \& Jayerate, T. (1973). "The queen bee syndrome". Psychology Today, 7(8), 55-60.

Student Learning Development, University of Otago. (2016). Writing a literature review. Dunedin: Otago University.

Walsh, M., Ortega, E., \& Heckman, B. (2016). The dental hygiene scholarly identity and roadblocks to achieving it. Journal of Dental Hygiene, 90(2), 79-87. Retrieved from http://search.ebscohost.com/ login. aspx?direct $=$ true $\& \mathrm{db}=\mathrm{ccm} \& \mathrm{AN}=115330219 \&$ site $=$ ehost-live Wickham, S. (2012). Top ten tips on turning an assignment into an article. Essentially MIDIRS, 3(7), 27-31. Retrieved from https:// www.midirs.org/wp-content/uploads/2012/12/Essentially-MIDIRS\%E2\%80\%93-Jul-Aug-2012-Top-Ten.pdf

Williams, H. C. (2004). How to reply to referees' comments when submitting manuscripts for publication. Journal of the American Academy of Dermatology, 51(1), 79-83. doi: https://doi.org/10.1016/j. jaad.2004.01.049

Wood, C. (2018). Writing for publication: Sharing your clinical knowledge and skills. British Journal of Community Nursing, 23(1), 2023. https://doi.org/10.12968/bjen.2018.23.1.20

\section{Accepted for Publication June 2020}

Patterson, J. \& Gilkison, A. (2020). Writing a journal article from your thesis or research project. New Zealand College of Midwives Journal, 56, 13-16.

https://doi.org/10.12784/nzcomjnl56.2020.2.13-16 